\title{
Inhalt des 27. Bandes
}

\section{Heft 1}

Der.trt, L., Signal Parameters in Optical Pumping Experiments . . . . . . . . . . . . 1 HaAN, O., Consequences of Crossed Channel Structure for High Energy Elastic Scattering . 35

\section{Heft 2/3}

GeYer, B., Robaschik, D., and E. Wieczorek, Theory of Deep Inelastic Lepton-Hadron

Scattering . . . . . . . . . . . . . . . . . . . . . . . 75

\section{Heft 4}

Heck, L., The Algebraic Structure of the Thirring Model . . . . . . . . . . . . . . . 169

Niederer, U., Massless Fields as Unitary Representations of the Poincaré Group . . . . . 191

\section{Heft 5}

BAIER, H., Exchange Currents, Isobaric Excitations and the Deuteron . . . . . . . . . 209

\section{Heft 6}

CARMeri, M., and M. KAYE, Einstein-Maxwell Equations: Gauge Formulation and Solutions for Radiating Bodies . . . . . . . . . . . . . . . . . . . . . . . . . . . 261

\section{Heft 7}

Daibog, E. I., Rosental, I. L., and Ju. A. Tarasov, Hydrodynamical Theory of High-Energy Particles Interaction . . . . . . . . . . . . . . . . . . . . . 313

\section{Heft 8}

Kalashnikov, V.P., and M. I. Auslemder, Generating Functionals in Nonequilibrium Statistical Mechanics. . . . . . . . . . . . . . . . . . . . . . . . . 355

\section{Heft 9}

Debničková, A. Z., Efimov, G. V., and M. A. Ivanov, Nonlocal Quark Model and Meson

Decays . . . . . . . . . . . . . . . . . . . . . . . . . 403

BÁNyaI, L., and A. ALdEA, Master Equation Approach to the Hopping Transport Theory . . 435 


\section{Heft 10}

KobayashI, M., Polarization-Phenomena in Elastic Electron-Proton Scattering . . . . . . 463 DrEchsLer, W., Heisenberg Equations of Motion in a Nonabelian Gauge Theory . . . . . 489

\section{Heft 11/12}

Marinov, M. S., and M. V. Terentyev, Dynamics on the Group Manifold and Path Integral 511 Dosch, H. G., and V. F. MüLLER, Lattice Gauge Theory in Two Spacetime Dimensions . . . 547 SingH, V., and A. K. RaINa, Bounds on Form Factors and Propagators . . . . . . . . . 561 KUPSOH, J., and W. RÜHL, On the Quantization of Hydrodynamics . . . . . . . . . . . 581 HofmanN, C., Die Bewertung optischer Systeme . . . . . . . . . . . . . 595 


\section{FORTSCHRITTE DER}

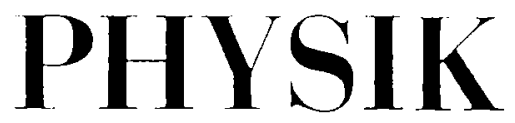

HERAUSGEGEBEN IM AUFTRAGE DER PHYSIKALISCHEN GESELLSCHAFT DER

DFUTSCHEN DHMOKRATISCHEN RFPUBLIK

VON F. KASCHI,UHN, A. LOSCHE, R. RITSCHL UND R. ROMPE

HEFT $1 \cdot 1979 \cdot$ BAND 27

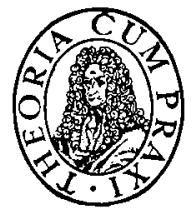

A K A D E M I E - V E R L A G • B E R L I N

EVP 10,- M 